\title{
AÇÃo COLETIVA E COOPERAÇÃO INTERMUNICIPAL EM DUAS METROOPOLES
}

\author{
Alan Daniel Freire de Lacerda*
}

\begin{abstract}
O texto tem como objetivo central elaborar uma teoria da ação coletiva pertinente à análise dos problemas de cooperação metropolitanos. Tomando como casos preliminares as regiões metropolitanas de Natal e Recife, o trabalho visa também a definir que incentivos os municípios componentes de tais regiões têm para colaborar na solução de problemas tipicamente intermunicipais. A opção teórico-metodológica do artigo leva à conclusão de que as questões relacionadas à gestão metropolitana não podem ser separadas de variáveis relativas à integração dos municípios à cidade-polo da região. O trabalho empírico efetuado na aplicação parcial do modelo sistematiza dados qualitativos e quantitativos de pesquisas feitas por outros autores sobre as duas regiões mencionadas.
\end{abstract}

PALAVRAS-CHAVE: cooperação, gestão, metrópoles.

\section{INTRODUÇÃO}

Neste artigo, elaboro um modelo teórico de ação coletiva metropolitana e faço uma aplicação parcial dele à investigação das regiões metropolitanas de Natal (RMN) e de Recife (RMR) a partir de suas facetas políticas e institucionais. Em particular, as relações de cooperação e conflito entre os municípios nas referidas regiões serão teorizadas. ${ }^{1}$

A governança metropolitana é um dos principais problemas do mundo globalizado. Metrópoles, em princípio, são cidades intermunicipais, o que amplia os desafios de sua gestão conjunta, em vista de estruturas de serviços que devem ser governadas com planejamento e estratégias mini-

* Doutor em Ciência Política. Professor da Universidade Federal do Rio Grande do Norte.

Centro de Ciências Humanas Letras e Artes, Departamento de Políticas Públicas. Campus Universitário Lagoa Nova. Caixa Postal 1524. Cep: 59072-970 - Natal Rio Grande do Norte - Brasil. lacerda75@msn.com

${ }^{1}$ Sou grato pelos comentários feitos por Ilza Andrade, Sandra Gomes, Lindijane Almeida e Joana Moura a versões anteriores deste texto. Erros eventualmente remanescentes são de responsabilidade do autor. Agradeço a Larissa Ferreira pela confecção dos mapas e também ao CNPq pelo apoio financeiro concedido à pesquisa da qua resultou este trabalho. mamente compatíveis entre os municípios que as compõem. O estatuto indefinido, do ponto de vis-

ta institucional, de muitas metrópoles contrasta com sua importância crescente na dinâmica econômica dos países e com o caráter complexo dos problemas urbanos que elas apresentam.

O caráter fluido dessas aglomerações como estrutura institucional se acentua no caso das metrópoles brasileiras nos anos recentes. De uma definição de metrópole instituída no plano da União pelo regime autoritário-militar, passou-se a uma situação, no período pós-1988, em que a responsabilidade pela criação das regiões metropolitanas é transferida aos estados. Tais entidades federadas, por uma série de razões, fragilizaram-se nos últimos anos em comparação com os municípios. Como consequência, considerações políticas relacionadas ao quadro de forças das assembleias legislativas de cada estado têm obtido força na regulação das RMs (Andrade; Clementino, 2007). No caso brasileiro, o status dos municípios como plenas entidades federadas, desde a Constituição de 1988, impõe novos desafios à cooperação. A rigor, é possível dizer que a cooperação 
intermunicipal metropolitana não tem como acontecer no Brasil se os entes municipais não apostarem nela como via de solução dos seus problemas. Quando os municípios se ausentam da estrutura de governança, soluções centralizadas, nos níveis estadual e federal, tornam-se mais atraentes para os atores pertinentes. Uma premissa deste trabalho é tomar o município, portanto, como unidade de análise nos problemas de ação coletiva relacionados ao viver metropolitano.

\section{UMA TEORIA DA AÇÃO COLETIVA INTERMUNICIPAL}

Que fatores podem criar obstáculos para a coordenação de políticas entre os municípios dentro de uma área metropolitana? É interessante pensar na coordenação intermunicipal e na criação das instituições correspondentes como meios para se realizar bens coletivos. ${ }^{2}$ Como tal, essas tentativas de coordenação entre atores estão potencialmente sujeitas à ocorrência de problemas de ação coletiva (Olson, 1999; Ostrom, 1990; ver, especificamente para o caso metropolitano, Feiock, 2004). O bem público puro, nessa acepção, se define classicamente por duas características centrais: indivisibilidade do suprimento e impossibilidade de exclusão.

\begin{abstract}
Se um bem tem suprimento indivisível, o consumo dele por parte de alguém não reduz o montante disponível para todos os outros. [...] Se um bem é caracterizado por impossibilidade de exclusão, é impossível impedir que pessoas relevantes o consumam (Hardin, 1982, p.17, tradução minha).
\end{abstract}

Orenstein (1998) chama a atenção para uma terceira característica: a não-rivalidade de consumo. Ela consiste na "propriedade pela qual o benefício para o consumidor de um bem não varia com o número de consumidores que demandam este mesmo bem” (p. 64). A rigor, poucos bens

2 Ao longo do texto, utilizo as expressões "bem coletivo" e "bem público" de maneira intercambiável. Da mesma forma, procedo com "cidades” e "municípios". Para cidades cuja extensão engloba áreas de mais de um município, uso o termo "metrópole" ou "cidade intermunicipal". coletivos são puros, ou seja, atendem às três características; a maioria dos bens públicos é impura. As três características conformam, portanto, um tipo ideal de bem. Importa notar, todavia, que bens privados se situam regularmente em oposição a essas três definições. Eles são: a) perfeitamente divisíveis (o bem pode ser apropriado em parcelas diferentes por diversos consumidores, e cada porção utilizada é subtraída do total disponível para os demais); b) exclusivos (o usufruto do bem é seletivo em relação ao grupo relevante de consumidores); e c) rivais (uma vez consumido por um indivíduo, o benefício remanescente do bem privado é nulo para outros).

Na teoria olsoniana, grupos pequenos têm maior chance de prover um bem público desejado pelos seus membros do que grupos grandes. A lógica do raciocínio é relativamente simples: os integrantes desses grupos percebem com maior nitidez o peso de sua contribuição para o provimento do bem público, enquanto os membros de grupos grandes percebem, racionalmente, que seu peso individual na consecução do bem é irrisório. No último caso, portanto, os indivíduos não têm incentivos suficientes para cooperar, e o bem público advindo dessa cooperação provavelmente não será provido. Essa lógica ditada pelo autointeresse é reforçada pelo caráter não-exclusivo do bem, pois os chamados free-riders ou "caroneiros" podem supor que se beneficiarão, de todo modo, no caso de provimento do bem, ainda que não contribuam para a ação coletiva pertinente.

Hardin aduz uma importante interpretação a respeito do tamanho do grupo, ao afirmar que a questão crucial para a resolução de problemas de ação coletiva é a superação da latência do grupo. Nos termos de Olson, grupos pequenos têm mais chances de superar sua latência e tornarem-se grupos privilegiados (privileged), enquanto grandes grupos tendem a continuar latentes, ou seja, sem conseguir suprir o bem que é do interesse comum de seus membros. O ponto é se haverá uma fração (subgrupo ou indivíduo) que se disporá, dada a razão entre benefício e custo, a assumir os custos do provimento do bem público. Caso o benefício 
supere em muito os custos da consecução do bem, até mesmo um grande grupo poderá superar sua latência, desde que uma fração dessa coletividade perceba que ganhará ainda que assuma todos os custos do provimento. Em geral, é mais fácil o surgimento dessa fração em grupos de menor dimensão (Hardin, p. 38-49).

Embora não cite o trabalho clássico de Olson, Souza (2006, p. 173) sugere que o problema metropolitano pode ser entendido nesses termos. Dado o grande número de agências e atores, sociais e institucionais "que atuam simultaneamente no mesmo espaço territorial”, a cooperação entre eles implica o mesmo desafio dos grupos grandes. Apesar de considerarmos a sugestão interessante, acreditamos que é necessário elaborar mais as implicações teóricas dessa posição analítica. ${ }^{3}$

Será verdade, por exemplo, que as metrópoles constituem grandes grupos? Se considerarmos a questão no plano dos municípios, tomando-os como atores individuais, a resposta é claramente negativa. A maior metrópole brasileira, São Paulo, tem 39 atores municipais, enquanto as metrópoles em foco neste estudo, Natal e Recife, possuem nove e catorze municípios, respectivamente. Ambas (ou possivelmente as três) se caracterizariam sem maiores dificuldades como grupos pequenos, possivelmente privilegiados, na terminologia olsoniana.

Nesse tipo de grupo, "cada um dos membros, ou ao menos um deles, achará que seu ganho pessoal ao obter o benefício coletivo excede o custo total de prover determinada quantidade desse benefício" (Olson, 1999, p. 46). É importante notar que os grupos pequenos podem alcançar uma provisão relativamente satisfatória do bem público, mesmo que um de seus integrantes arque com uma parte desproporcionalmente grande dos custos do bem público. Embora não estivesse entre seus propósitos analisar a coordenação entre municípios, Olson (p. 49) sugere isso explicitamente para o caso metropolitano:

${ }^{3}$ Garson (2009) também propõe, em análise mais detalhada, o uso de modelos teóricos de ação coletiva. No entanto, seu trabalho não aplica diretamente na análise empírica o arcabouço conceitual derivado do livro clássico de Olson.
Poderia ainda sugerir que os governos municipais vizinhos em áreas metropolitanas que proveem benefícios coletivos (como estradas vicinais e melhorias na área educacional) que favorecem a população de dois ou mais municípios da região tendem a prover quantidades inadequadas desses serviços e que o município maior (...) arcaria com uma parte desproporcional dos custos de provê-los.

Mesmo pequenos grupos, portanto, terão dificuldades de alcançar um nível ótimo de provisão do bem público, mas suas chances de obter algum montante do bem são maiores que as dos grandes grupos. O ponto reside, novamente, na percepção que cada integrante tem do peso de sua contribuição para a consecução do bem público. Em grupos privilegiados, a promoção dos interesses comuns de seus membros se torna facilitada pela simples atração que a perspectiva da obtenção do bem público provoca em cada um deles. Não é necessário o uso de um incentivo seletivo, seja ele negativo (coerção) ou positivo (recompensas), como é com frequência o caso nos grupos latentes. Como se sabe, a aplicação desse incentivo depende da criação e manutenção de organizações ou instituições, cuja origem também supõe, em geral, a solução de problemas de ação coletiva.

A definição do que é ou não um grupo pequeno corre o risco de ser arbitrária? Existe um "ponto de corte" em número de integrantes a partir do qual um grupo deixa de ser pequeno e se torna intermediário ${ }^{4}$ ou grande? De novo, "a resposta dependerá se os atos individuais de um ou mais membros do grupo são perceptíveis para qualquer outro membro do grupo" (Olson, 1999, p. 58) e se uma fração, indivíduo ou subgrupo, do grupo percebe que ganhará, mesmo se tolerar a nãocooperação da maioria dos integrantes. Enquanto esse for o caso, podemos classificar um determinado grupo como privilegiado.

Na medida em que o município maior da área metropolitana pode assumir a maior parte dos custos da provisão de uma série de bens públicos,

${ }^{4} \mathrm{Na}$ formulação de Olson, o grupo intermediário pode ou não prover o bem público para seus integrantes, mas dificilmente o fará sem algum tipo de acordo ou organização grupal. Ele considera que oligopólios se encaixam com frequência nesse caso. 
cabe indagar, em cada caso, se suas ações são claramente perceptíveis para os outros municípios da metrópole. Se a resposta é sim, a extensão em que a percepção ocorre passa a ser importante para o grau de provimento do bem publico. Os municípios menores podem acreditar, por exemplo, que o esforço atual da sede metropolitana é suficiente para a consecução adequada do bem, enquanto, na realidade, seu esforço próprio deveria ser maior para esse fim. O resultado é uma realização subótima do bem. Portanto, mesmo em "grupos menores [...] o beneficio coletivo geralmente não será provido em um nível ótimo. Ou seja, os membros do grupo não proverão toda a quantidade de beneficio coletivo que seria de seu interesse comum prover." (Olson, 1999, p. 47). Essa situação configura o que chamo de problema de percepção.

Por que realizar, entretanto, bens coletivos que atendam a toda uma região metropolitana? Por que criar um arranjo institucional que propicie a realização de bens coletivos substantivos para todos os municípios metropolitanos? Por que não deixar, como sugere o atual arranjo federativo brasileiro, que cada município cuide de sua seara?

A resposta a essas perguntas reside, crucialmente, no fato de que as ações de cada cidade produzem custos relevantes para as demais, especialmente em uma metrópole. A expansão de bairros da cidade-polo em municípios vizinhos cria problemas habitacionais e de saneamento antes inexistentes nessas aglomerações menores. Prefeituras, na região, podem superlotar os hospitais da cidade maior ao comprar ambulâncias para enviar seus pacientes ao grande centro. Políticas de saneamento definidas no nível municipal podem fracassar diante das demandas sanitárias conjuntas da região. Policiamento reforçado na capital pode implicar migração de criminosos para as cidades periféricas. "Na origem de um bem coletivo há sempre um mal coletivo", assevera propriamente Orenstein (1998, p. 67-68).

O mal público tem características similares às dos bens públicos, na medida em que "impõe custos obrigatórios e simultâneos a um conjunto de indivíduos" (1998, p. 68). Males coletivos po- dem ser, dependendo de sua origem, sociais ou naturais. Trataremos aqui, evidentemente, de males coletivos inerentemente sociais.

A esse respeito, Santos (1993) elabora uma lógica dual da ação coletiva em que bens públicos são produzidos por uma coletividade em resposta a males públicos que lhe são impostos por outra coletividade. Em sua análise, a classe operária e a classe capitalista, em diversos episódios da história brasileira, enfrentaram e, por vezes, solucionaram o problema de ação coletiva representado pelo consumo gratuito do bem público - ou seja, impediram o consumo dos "caronas". O ator maximizante não precisa, nesse caso, ser altruísta: ele só precisa perceber que a não-provisão do bem coletivo aumentará a probabilidade do mal público gerado pela outra classe social. ${ }^{5}$

A introdução do conceito de mal público metropolitano na análise permite refinar o entendimento dos problemas metropolitanos de coordenação intermunicipal. Denomino mal público metropolitano os custos compulsórios consumidos por um município em função de sua integração socioespacial a uma região metropolitana. Tais custos podem ser sanitários, habitacionais ou relacionados à execução das mais diversas políticas públicas, e são causados por condutas (ativamente perseguidas ou relativamente toleradas) de outros municípios na região. É parte integrante dessa definição a noção de que o consumo compulsório do mal público pode ser interrompido ou efetivamente reduzido via cooperação intermunicipal. Também pressuponho aqui que tais custos compulsórios são, em algum momento, percebidos pelos entes municipais.

Substantivamente falando, em que contextos metropolitanos a ocorrência de males públicos é mais provável? A resposta a essa pergunta supõe clareza na definição do próprio problema metropolitano. Não se deve aceitar prima facie a premis-

${ }^{5}$ Organizações de classe empresarial apoiaram, por exemplo, a regulamentação da jornada de trabalho para evitar o mal coletivo (de seu ponto de vista) reivindicado pelos operários: a jornada diária de oito horas de trabalho. A regulamentação única impediria a estratégia do "carona" de alguns empresários que negociavam com seus trabalhadores a jornada sem arcar com os custos da ação coletiva empresarial junto ao governo. Cf. Santos (1993, p. 59-63). 
sa de que os municípios integrantes de uma metrópole têm de cooperar para melhorar sua situação só porque estão agregados formalmente em uma RM. É preciso considerar se há ou não, por exemplo, grande assimetria no consumo do mal coletivo gerado pela convivência metropolitana. Municípios pouco atingidos pelos problemas habitacionais, ambientais e sociais dessa convivência não têm incentivos para investir na criação e manutenção dos arranjos institucionais das RMs.

Cabe, portanto, identificar nas metrópoles a precisa relação entre atores municipais e incidência de mal público metropolitano. Proponho que essa relação seja localizada na variável relativa à integração de cada município ao polo metropolitano. Entes municipais basicamente rurais e (ou) fracamente integrados à dinâmica do aglomerado simplesmente não estão consumindo intensamente os custos de viver em uma metrópole. Não possuem, por isso mesmo, o desejo de interromper ou reduzir tal consumo, investindo esforços no fortalecimento dos conselhos das RMs - um bem público - nos quais tomam assento. Essa questão se torna ainda mais pertinente se lembrarmos que a inclusão de municípios nas RMs tem obedecido, em algumas ocasiões, a critérios relacionados à promoção política de prefeitos e cidades.

Felizmente, a literatura já apresenta classificações relacionadas ao grau de integração dos municípios, inclusive para as duas RMs que são objeto de minha atenção aqui. A classificação usada pela rede de pesquisa Observatório das Metrópoles (Ribeiro, 2009), por exemplo, compõe-se de variáveis relativamente bem definidas e mensuráveis:

- Número de pessoas ocupadas em atividades nãoagrícolas.

- Densidade demográfica.

- Número de pessoas que trabalham ou estudam em outros municípios.

- Taxa de crescimento populacional.

Como se pode notar, os dois primeiros indicadores medem indiretamente o grau de urbanização do município. O terceiro registra a taxa de movimento pendular, tão característica de metró- poles, relacionada à busca de oportunidades de ascensão social (ele tende a ser muito baixo no caso do município polo, pois este já provê, em grande medida, essas oportunidades para quem mora nele). O quarto procura identificar em que grau a população vem crescendo, inclusive além do que seria suposto prever pelo mero crescimento vegetativo. Cabe notar que todos esses indicadores podem registrar valores significativos em situações não-metropolitanas, mas o pressuposto aqui é de que, nas regiões conurbadas, tais números tendem a ser regularmente altos.

Os indicadores são agrupados mediante análise fatorial em um índice que varia de 0 a 1, definindo concretamente níveis de integração à dinâmica da aglomeração, de muito baixo a muito alto.

A lógica de custo-benefício presente em minha análise possibilita que classifiquemos de maneira mais específica os pequenos municípios da RM formal que não estão de fato substancialmente integrados na dinâmica dos aglomerados urbanos. Nos casos em que eles pouco ou nada investem na cooperação intermunicipal, estaríamos diante de "caronas"?

A resposta é claramente negativa nas regiões nas quais inexistem recursos especificamente normatizados, a exemplo dos fundos metropolitanos. No caso, os entes municipais mencionados estão apenas aproveitando a oportunidade política representada pela aprovação legislativa de sua inserção na região. Participarão da estrutura de governança (conselhos metropolitanos) apenas nas ocasiões em que os ganhos de oportunidade política são claros, ou quando recursos destinados para a região estiverem em jogo. Em vez de free-riders, portanto, teríamos opportunity-seekers. ${ }^{6}$

No caso de regiões onde a integração é, no mínimo, média, a existência de free-riders se torna mais provável, e o problema de percepção olsoniano se aplica com toda propriedade. Se pequenos municípios entendem que o polo já provê satisfatoriamente os bens públicos substantivos da

${ }^{6}$ Nas RMs em que há tanto municípios fracamente integrados à dinâmica da aglomeração quanto fundos metropolitanos previstos em lei, é possível que existam as duas categorias ao mesmo tempo. 
convivência metropolitana, eles podem optar por participar menos das estruturas de gestão regionais, apesar de receberem recursos do fundo metropolitano correspondente. Essa conduta, por sua vez, pode ocasionar o não-provimento desses bens ou sua realização em escala insuficiente.

Tanto free-riders quanto opportunity-seekers são deletérios ao quadro financeiro do urbano no Brasil. A esse respeito, é interessante notar que o problema de ação coletiva metropolitano, tal como se coloca no Brasil pós-1988, adquire facetas similares ao chamado problema ou tragédia do "Commons" (Hardin, 1968; Ostrom, 1990). Em sua formulação original, Garrett Hardin exemplifica o problema com uma área de pasto usada em comum por uma coletividade de pastores.

Figura 1 - Resumo do modelo

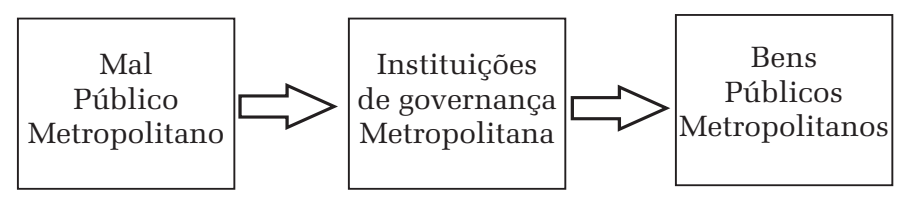
Cada pastor recebe benefícios diretos do uso de seus animais e sofre custos quando ocorre uso excessivo do pasto por parte de seu próprio gado e daquele dos demais pastores. Entretanto, cada indivíduo tem incentivos para agregar mais animais ao pasto comum, uma vez que ele espera obter mais recompensas com essa ação e que isso superará os custos individuais do excesso de utilização do pasto - em todo caso, cada pastor arca com apenas uma parcela do custo total. Dado o fato de que os recursos naturais são limitados, o resultado é a deterioração geral do pasto para todos os pastores - embora o comportamento de cada um tenha sido racional.

No cenário institucional pós-1988, houve uma ampliação concomitante do acesso dos municípios a verbas federais e das possibilidades de criação de regiões metropolitanas legais por parte dos estados. Essas regiões, por sua vez, constituem novas razões para que os municípios pleiteiem recursos da União. As demandas dos cidadãos das urbes, de outro lado, também só fizeram aumentar, a partir do próprio aumento populacional das cidades e da concessão de direitos sociais no texto constitucional. Torna-se mais proveitoso, para cada município, usar ao máximo esse acesso ampliado a verbas de origem predominantemente federal. Todavia, para os municípios em conjunto, os cus- tos da sobreutilização dos recursos, por finitos, são consideráveis, já que eles são alocados de fontes não muito diversificadas (Clementino, 2008). O resultado é similar ao do famoso modelo da tragédia do "Commons": deterioração da receita conjunta destinada aos entes metropolitanos.

A Figura 1 abaixo resume os aspectos centrais de meu modelo, destacando o percurso que conduz dos custos assumidos pelos municípios à produção de bens públicos cujo papel é reduzir tais custos. 
ras regiões metropolitanas do Brasil: São Paulo, Belo Horizonte, Porto Alegre, Recife, Salvador, Curitiba, Belém e Fortaleza. ${ }^{7}$ Deve-se destacar que não havia legislação infraconstitucional pertinente às metrópoles antes dessa lei complementar. Uma breve referência na forma do Art.164 da Constituição de 1969 provia a futura criação dessas áreas por lei complementar, coisa que aconteceu, como se vê, quase quatro anos depois. $\mathrm{O}$ artigo facultava à União a capacidade de criar, via lei complementar, regiões metropolitanas, "constituídas por municípios que, independentemente de sua vinculação administrativa”, fizessem "parte da mesma comunidade socioeconômica."

Apesar de ter sido aprovada no regime autoritário-militar, a Lei Complementar n. 14 não é uma peça legal com objetivos autoritários em seu conteúdo. É verdade, por um lado, que a lei definiu a composição municipal das regiões sem consultas aos agentes locais relevantes e estabeleceu um formato único para todas as RMs sem atentar para particularidades regionais. Por outro lado, a competência gestora foi alocada para os estados na forma de um conselho deliberativo e um conselho consultivo para cada região, a serem criados por lei estadual. A direção do planejamento de cada RM ficou desde o início, portanto, a cargo dos estados, não da União, embora houvesse, é claro, uma política nacional de planejamento urbano. ${ }^{8}$

A Constituição de 1988 inaugura um novo momento (Moura; Delgado; Deschamps; Castello Branco, 2007) na institucionalização das RMs e outras categorias de organização espacial relacionadas ao urbano. O Art. 25 do texto constitucio-

${ }^{7}$ A região metropolitana do Rio de Janeiro só foi criada em 1974 com a Lei Complementar n. 20, de $1^{\circ}$. de julho de 1974, que fundiu os estados da Guanabara e do Rio de Janeiro.

${ }^{8}$ No texto da lei, o conselho deliberativo é composto por cinco pessoas nomeadas pelo governador do Estado. Dentre os cinco integrantes, um deve figurar em lista tríplice elaborada pelo prefeito da capital e outro ser indicado pelos demais municípios. O conselho consultivo é presidido pelo presidente do conselho deliberativo, senpresidido pelo presidente do conselho deliberativo, sentegrante da RM. É possível perceber que, apesar de uniformizador, o arranjo institucional previsto na lei não é tão rígido e centralizador, considerado em si próprio. O que o torna visivelmente restritivo, do ponto de vista dos municípios, é a provisão vigente na época de nomeação dos prefeitos das capitais pelos governadores. nal delega aos estados a responsabilidade de criar as referidas regiões, assim como aglomerações urbanas e microrregiões compostas por municípios contíguos, estabelecendo como única condição que as leis estaduais com tais efeitos sejam complementares. ${ }^{9}$ Embora a gestão e o planejamento das RMs continuem sendo responsabilidade estadual, a União perde o poder legal de instituir áreas metropolitanas. A definição de serviços públicos comuns de interesse dos municípios metropolitanos também sai por completo da esfera federal. O impulso descentralizador do novo texto constitucional, é óbvio, e não precisa de maior ênfase.

Nos termos da Lei Complementar n. 14, a Região Metropolitana de Recife começou englobando nove municípios: Recife, Cabo de Santo Agostinho, Igarassu, Ilha de Itamaracá, Jaboatão dos Guararapes, Moreno, Olinda, Paulista e São João da Mata. Desmembramentos posteriores incluíram na região os municípios de Abreu e Lima, Itapissuma, Araçoiaba e Camaragibe. Em 1994, foi adicionado o município de Ipojuca, perfazendo um total de catorze entes municipais nesse momento. ${ }^{10} \mathrm{O}$ Mapa 1 exibe a atual configuração da região recifense.

Apesar das alterações legais ocorridas de 1974 até hoje, o núcleo decisório formal da gestão metropolitana de Recife sempre foi o seu Conselho de Desenvolvimento, denominado CONDERM. No princípio, os conselhos consultivo e deliberativo que compunham o CONDERM exibiam, em consonância com a legislação federal, clara preponderância do governo estadual. O governador de Pernambuco, por exemplo, presidia o conselho deliberativo e, por conseguinte, o consultivo também.

Leis estaduais de 1975 também criaram a Fundação de Desenvolvimento da Região Metropolitana do Recife (FIDEM) e o Fundo de Desenvolvimento da Região Metropolitana do Recife (FUNDERM). Ambos ainda existem atualmente. Como os conselhos não se reuniam com frequência, a FIDEM, um órgão vinculado à secretaria estadu-

${ }^{9}$ Tais leis exigem, em geral, o patamar de maioria absoluta de votos no corpo legislativo para lograr aprovação.

${ }^{10}$ As informações sobre o funcionamento e estrutura da RMR foram retiradas de Clementino e Souza (2009). 
Mapa 1 - Municípios da Região Metropolitana de Recife

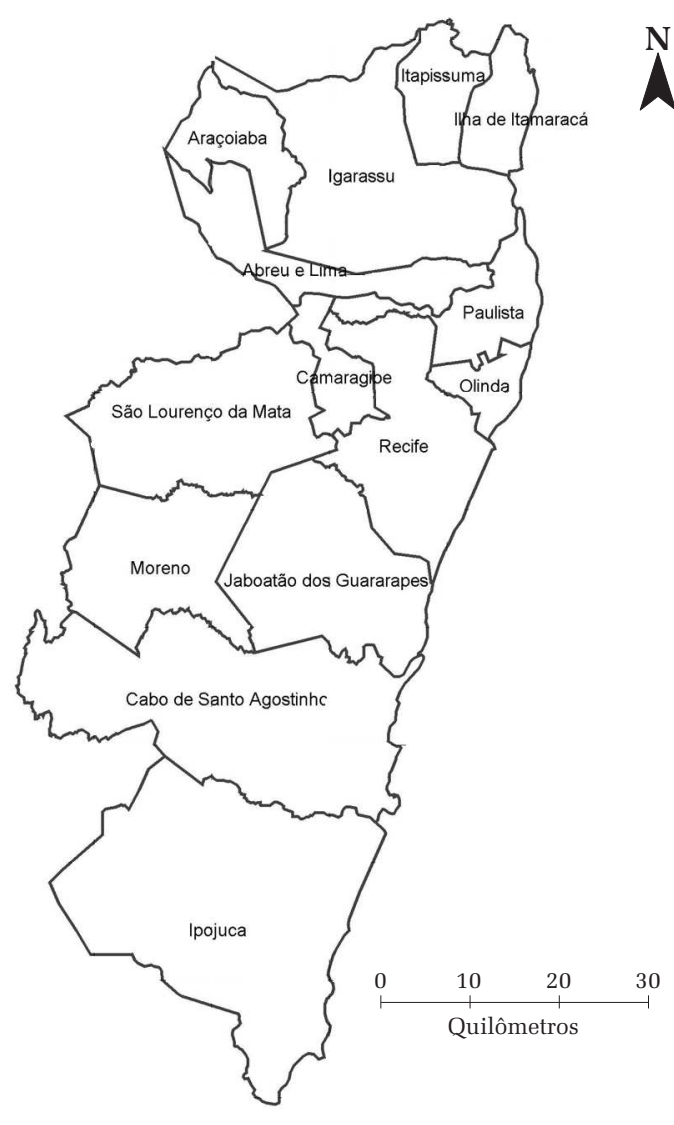

Fonte: Mapa base do IBGE, 2005. Elaborado no Núcleo RMNatal - INCT. Observatório das Metrópoles, 2010.

al de Planejamento, foi adquirindo certa primazia na gestão metropolitana, inclusive na gestão e distribuição dos recursos do referido fundo. Politicamente falando, os municípios detinham baixa influência sobre o sistema de gestão metropolitano como tal até o fim dos anos 80.

Após a Constituição de 1988, o CONDERM passa a ser presidido pelo secretário de Planejamento do Estado, sendo composto pelos prefeitos municipais da RMR e por um número igual de membros indicados pelo governador. ${ }^{11}$ Ogoverno estadual conta, portanto, com maioria de votos no conselho. Além disso, a secretaria executiva e de apoio técnico do órgão é a agência CONDEPE/FIDEM, autarquia vinculada à secretaria de Planejamento .

${ }^{11}$ Há também, no CONDERM, representantes consultivos da Assembleia Legislativa e das câmaras municipais da região, sem direito a voto.
É interessante notar que, segundo o Art.2 da Lei Complementar n. 10, de 06 de janeiro de 1994, a ampliação da RMR "está condicionada" à "evidência ou tendência de conurbação", entre outros critérios técnicos. Assim, a própria peça legislativa estadual que regula a composição da região cria restrições à expansão da área metropolitana legal. Embora não existissem consórcios intermunicipais na RMR até 2006, várias ações que envolvem cooperação entre os municípios têm sido executadas via sistema gestor metropolitano, com destaque para a urbanização de morros e áreas de baixa renda em geral. Não por acaso, o CONDERM é decisivamente assessorado por câmaras técnicas setoriais.

A Região Metropolitana de Natal foi instituída em 16 de janeiro de 1997, fruto de um projeto de lei da deputada Fátima Bezerra (PT), que logrou ser aprovado na Assembleia Legislativa na forma da Lei Complementar n.152. O principal órgão de gestão metropolitana é vinculado à secretaria estadual de Planejamento e Finanças: o Conselho de Desenvolvimento Metropolitano de Natal (CDMN), cujas reuniões começaram a partir de 2001 (Clementino, 2004; Andrade, 2008). A lei complementar que deu origem à região incluiu nela os municípios de Natal, Parnamirim, Macaíba, São Gonçalo do Amarante, Extremoz e Ceará-Mirim. Alterações legislativas posteriores também trouxeram para a região as cidades de Nísia Floresta, São José do Mipibu e Monte Alegre, perfazendo um total de nove municípios até 2008. OMapa 2 mostra a configuração da região em 2008.

Até 2002, o CDMN era composto formalmente pelo seu presidente, o secretário de Planejamento e Finanças, além de cinco ou seis integrantes indicados pelo governador do Estado a partir de uma lista tríplice elaborada pelos prefeitos e câmaras municipais de cada município. A composição atual do CDMN compreende os nove prefeitos municipais, um vereador que representa o chamado Parlamento Comum da RMN, um deputado estadual na qualidade de representante da Assembleia Legislativa e o secretário de Planeja- 
Mapa 2 - Municípios da Região Metropolitana de Natal

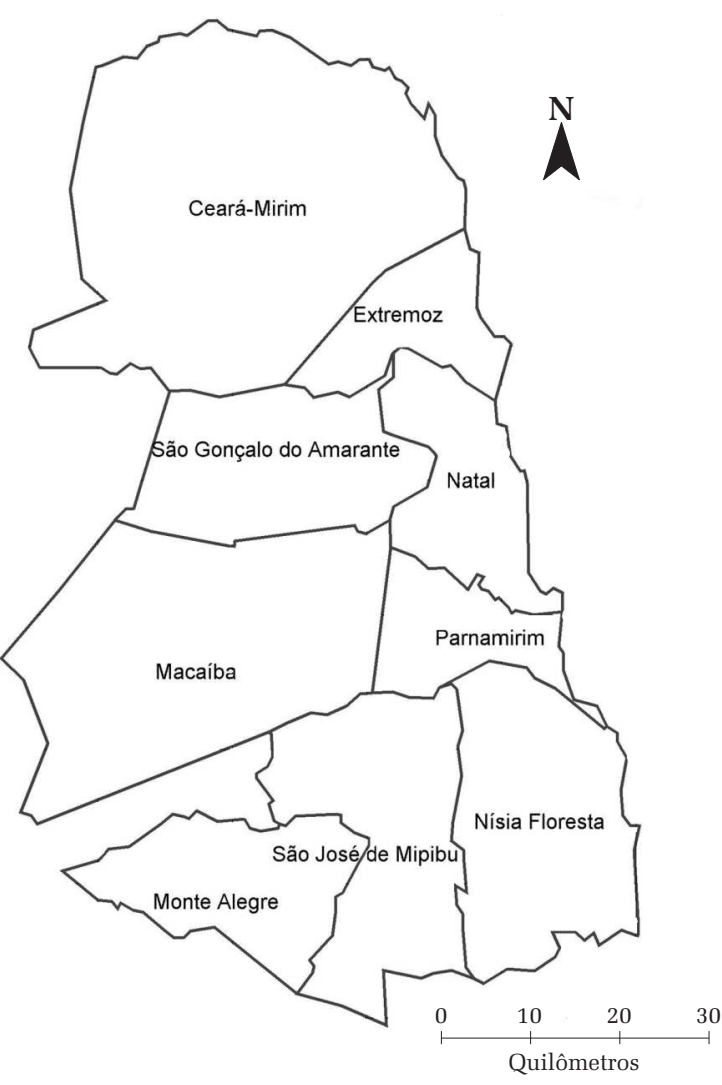

Fonte: Mapa base do IBGE, 2005. Elaborado no Núcleo RMNatal - INCT. Observatório das Metrópoles, 2010.

mento e Finanças, que continua a presidir o conselho. Como se pode ver, o governo estadual não conta, à diferença do caso de Recife, com maioria de votos no conselho metropolitano.

A cooperação entre os municípios da RMNé quase inexistente. Clementino (2005) registra, por exemplo, que inexistem consórcios intermunicipais na região nas áreas de saúde, habitação, educação, aquisição de máquinas e equipamentos, abastecimento d'água, esgotamento sanitário e limpeza/coleta de lixo. As reuniões do CDMN somente recentemente se tornaram mais frequentes, e há limitações em sua valência política como órgão deliberativo. Para citar um exemplo, as negociações sobre o aterro sanitário metropolitano, iniciadas em primeiro lugar no âmbito do conselho, terminaram sendo desenvolvidas entre os municípios de Natal e Ceará-Mirim, sem qualquer participação efetiva do CDMN (Clementino,
2005). Não há, de resto, na legislação pertinente, a previsão de um fundo para amparar a gestão metropolitana.

De acordo com o Art. 23 de seu regimento interno, as deliberações do conselho se dão por voto majoritário com igual peso entre os municípios. Nesse sentido, a sede metropolitana - Natal tem poucos incentivos para participar mais efetivamente do órgão, uma vez que seu poder decisório é igual ao de municípios bem menores na região. A participação dos prefeitos ou de seus representantes nas reuniões do CDMN também é limitada, e tais encontros têm sido infrequentes (Andrade, 2008). Na prática, o conselho é um fórum cuja capacidade deliberativa ainda não se efetivou. A ação mais interessante foi mesmo a criação do Parlamento Comum, que se converteu em um polo de debates quando de sua criação em 2001 (Clementino, 2005). Por fim, é importante destacar que inexistem, na legislação, restrições à expansão da RMN com a inclusão de novos municípios. ${ }^{12}$

O Quadro 1 sumariza as principais características das duas regiões.

Quadro 1 - Comparativo das regióes metropolitanas de Recife e Natal

\begin{tabular}{|l|l|l|}
\hline \multicolumn{1}{|c|}{ Características } & \multicolumn{1}{|c|}{ Recife } & \multicolumn{1}{c|}{ Natal } \\
\hline Fundo próprio & Sim & Não \\
\hline $\begin{array}{l}\text { Regra de } \\
\text { decisão no } \\
\text { conselho }\end{array}$ & $\begin{array}{l}\text { Voto majoritário } \\
\text { com igual peso } \\
\text { entre os } \\
\text { municípios }\end{array}$ & $\begin{array}{l}\text { Voto majoritário } \\
\text { com igual peso } \\
\text { entre os } \\
\text { municípios }\end{array}$ \\
\hline $\begin{array}{l}\text { Participação do } \\
\text { governo } \\
\text { estadual no } \\
\text { conselho }\end{array}$ & $\begin{array}{l}\text { Majoritária com } \\
\text { presidência }\end{array}$ & $\begin{array}{l}\text { Minoritária com } \\
\text { presidência }\end{array}$ \\
\hline $\begin{array}{l}\text { Período de } \\
\text { criação }\end{array}$ & Pré-1988 & Pós-1988 \\
\hline $\begin{array}{l}\text { Número de } \\
\text { entes } \\
\text { municipais }\end{array}$ & $\begin{array}{l}\text { Qritérios técnicos } \\
\text { claros }\end{array}$ & $\begin{array}{l}\text { Critérios técnicos } \\
\text { difusos }\end{array}$ \\
\hline $\begin{array}{l}\text { Regra de } \\
\text { ingresso }\end{array}$ & Nove \\
\hline
\end{tabular}

12 O Art. 1 apenas especifica que mais municípios poderão ser integrados à região a partir de "demanda por serviços", "necessidade de investimentos e parcerias", ou ainda "motivados por sua expansão urbana acelerada”. Tais requisitos não têm, a meu ver, tradução técnica rigorosa. 
Não se deve examinar, todavia, as duas RMs de uma forma isolada das implicações do regramento institucional que regula atualmente as metrópoles legais brasileiras. Como Andrade e Clementino (2007) sustentam, a atual estrutura institucional que regula a criação e a gestão das metrópoles no Brasil carece de incentivos suficientes para fomentar a cooperação entre os municípios dessas regiões. Três parecem ser, em nível macro, as razões institucionais desse fato:

a) As feições descentralizadoras da Constituição de 1988 melhoraram a fatia de recursos destinada aos municípios, sobretudo a partir das transferências automáticas de verbas, mas a centralização de recursos no plano federal ainda mantém esse ente federadona dependência da União. Particularmente, municípios que se propõem a cooperar em uma mesma região metropolitana podem ser competidores na disputa por repasses federais oriundos de convênios (portanto, não-automáticos e não-determinados no texto constitucional).

b) Como o texto constitucional vigente transfere para os estados a atribuição de criar regiões metropolitanas, ele retira do nível federal a responsabilidade de gerar uma política urbana nacional a partir da regulação dessas aglomerações urbanas. Com isso, o governo federal perde os incentivos para se transmutar em um ator externo, tal como o Leviatã hobbesiano, que proveria a cooperação entre municipalidades metropolitanas em situações de ausência completa de cooperação entre os entes municipais. As relações entre os prefeitos e o executivo federal passam a depender fortemente de afinidades políticas ocasionais.

c) Como as assembleias legislativas estaduais, em conjunto com os governadores, tornam-se as formuladoras de novas metrópoles com estatuto legal, os deputados estaduais têm incentivos para promover a inclusão de novos municípios nas RMs por motivos políticos. Essas ações podem se dar, por exemplo, como forma de prestigiar prefeitos e líderes locais dos municípios incluídos, que teriam, assim, uma espécie de "promoção". Tal inclusão também pode ter como objetivo a busca de verbas federais por parte dos pe- quenos municípios próximos à sede metropolitana. Como tais cidades não necessariamente se sentem pertencentes à metrópole, ou sequer são espacial ou economicamente vinculadas à sede, novos problemas políticos de coordenação emergem com esse tipo de inserção.

\section{CONSUMO DO MAL COLETIVO E CENÁRIOS COOPERATIVOS}

Como se apresenta a situação dos nossos dois casos no tocante à integração dos componentes na dinâmica metropolitana e, por conseguinte, no consumo do mal coletivo correspondente? Os dados demonstram a existência de heterogeneidade em ambas as RMs, como seria de esperar, mas o nível de diferenciação interna aponta variação entre as duas regiões. Comecemos com o caso de Natal a partir da literatura produzida nos últimos anos.

Gomes (2009), por exemplo, diferencia os municípios da RMN que compõem uma mancha urbana contínua - Natal, Parnamirim, São Gonçalo do Amarante e Macaíba - das cidades cujo "tempo" de reprodução do capital é lento e que são basicamente "centros locais": Nísia Floresta, Monte Alegre, São José do Mipibu, Ceará-Mirim e Extremoz.

Em outro registro, Pessoa (2009) também detecta variação similar ${ }^{13}$ a partir do exame dos movimentos pendulares de populações no interior do espaço metropolitano em busca de oportunidades de trabalho e educação. O movimento pendular é mais intenso nos municípios mais integrados ao polo metropolitano - os dados da autora também indicam que Extremoz já apresenta elevadas taxas dessa variável.

Por sua vez, a tipologia socioespacial construída a partir de categorias ocupacionais e sua distribuição no território - apresentada em Clementino e Pessoa (2009) detecta forte composição agrícola nos municípios de Monte Alegre, São José de Mipibu, Ceará-Mirim e Nísia Floresta. Como uma espécie de resumo da questão, o trabalho Como

${ }^{13}$ Com a ressalva de que sua análise não inclui o município de Monte Alegre. 
anda Natal (p.10-11) define níveis de integração a partir de variáveis como ocupação não-agrícola e densidade populacional. O escore que identifica alta integração é atingido em sua plenitude apenas por Parnamirim, cuja população é a única a superar a marca de 100 mil habitantes. São Gonçalo do Amarante vem em seguida, apresentando alta integração na dinâmica da aglomeração, enquanto Extremoz e Macaíba exibem média integração. Níveis de integração baixa são as características de Ceará-Mirim, Nísia Floresta e São José de Mipibu. ${ }^{14}$ O trabalho considera, em um juízo global, que Natal ainda é "uma metrópole em formação".

Situação diversa é encontrada na metrópole recifense. Nenhum município apresenta baixa integraçãoà dinâmica da aglomeração metropolitana, apesar da heterogeneidade verificada no perfil ocupacional dos entes municipais no trabalho Como anda Recife. Mesmo em municípios onde há atividade agrícola relevante, como Ipojuca, Moreno e São Lourenço da Mata, a integração à dinâmica metropolitana é considerada média por especialistas (p. 101).

Evidentemente, a restrição legal de natureza técnica à inclusão de novos municípios contribui para tal resultado. Por assim dizer, as regras da Região Metropolitana de Recife e seu desenvolvimento histórico asseguram que apenas entes municipais que efetivamente consomem uma parcela relevante de mal público metropolitano sejam incluídos na região. Cabe lembrar que, à exceção de desmembramentos resultantes de emancipações municipais, a única adição à RMR desde sua criação foi a de Ipojuca em 1994. Somente nesse ponto, portanto, a região sofreu expansão territorial propriamente falando.

A Grande Recife não deixa de apresentar um núcleo conurbado que, de fato, centraliza a dinâmica de todo o aglomerado, representado por Recife e pelos municípios populosos de Olinda, Jaboatão dos Guararapes e Paulista. A heterogeneidade resultante, inclusive em termos de movimentos pendulares e perfil sócio-ocupacional, é conside-

${ }^{14}$ Apesar de não incluir Monte Alegre, é aceitável presumir, a partir da análise, que seu nível de integração seja baixo ou muito baixo. rável e impõe presumíveis problemas de cooperação. Eles são atenuados, entretanto, pela resiliência do quadro de sócios integrantes da metrópole.

A análise precedente já deixou implícitas as circunstâncias em que os incentivos para a cooperação intermunicipal em nossos dois casos aumentam. No que toca à RMR, é justamente quando os custos do mal coletivo metropolitano para um dado município superam os benefícios advindos do consumo gratuito dos bens públicos gerados pela estrutura de gestão regional. A participação deficiente ou ausente na gestão da metrópole torna mais provável que o município seja atingido por diversos problemas da convivência metropolitana, especialmente se, como é frequente, a quantidade de mal coletivo for crescente no tempo em áreas como segurança pública, saneamento e habitação. Obviamente, mesmo quando a estrutura de incentivos dos sócios é favorável, o governo estadual é um ator fundamental na coordenação intermunicipal, na medida em que tem maioria de votos no conselho e pode propor formas de manejo das verbas do Funderm.

Em relaçãoà RMN, a equação é mais complexa. Os entes municipais fracamente integrados à dinâmica daaglomeraçãourbano-metropolitana nãotêm incentivos para cooperar, uma vez que seu consumo do mal coletivo pertinente é muito baixo ou reduzido. A indução para que eles cooperem deve provir necessariamente de movimentos específicos de governança que reconheçam seu cálculo distinto de custos e benefícios. Um exemplo seria a instituição de um fundo que condicionasse o acesso a seus recursos à participação dos municípios nas instâncias políticas e técnicas de deliberação metropolitana.

Os entes mais fortemente integrados à região fariam um cálculo de participação similar ao descrito no parágrafo anterior para os componentes do aglomerado recifense, com a observação de que, no caso de Natal, a estrutura de gestão regional ainda não fornece um fluxo regular de benefícios. Ou seja, a instituição de um fundo seria fundamental para incentivar a cooperação em qualquer caso.

Entretanto, o consumo assimétrico do mal público metropolitano levanta um problema para 
os entes municipais conurbados ou quaseconurbados no aglomerado natalense: por que participar de uma estrutura de gestão regional conjuntamente com municípios que pouco ou nada têm de metropolitanos? Por que dividir recursos com tais entes municipais, cujo consumo do mal público pertinente é tão baixo? Cabe lembrar que, se os custos da participação no $\mathrm{CDMN}$ forem iguais aos benefícios que dela advêm, os incentivos para a cooperação desaparecem. Uma solução possível de governança, nesse caso, é a instituição de peso maior nas votações do conselho para os municípios de alta e média integração, a começar por Natal.

Do ponto de vista analítico (e político), torna-se interessante identificar o nexo entre o consumo de mal coletivo e as estruturas de governança. Por um lado, é certo que preceitos estritamente igualitários de poder de voto dos entes municipais carregam consigo o signo de aprovação advindo de certos ideais democráticos. Por outro lado, descompassos entre a realidade substantiva da região e o arranjo institucional escolhido fazem emergir novos problemas de cooperação e dificultam a estabilização das regras do conselho metropolitano, como parece ser o caso do CDMN (Andrade, 2008). A resolução pontual desses descompassos pelo governo estadual não é óbvia e nem deve ser vista prima facie como a solução estável por excelência.

De resto, é interessante notar que o raciocí-

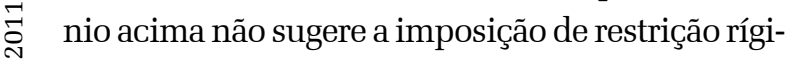
da à adição politicamente orientada de entes municipais às RMs. No limite, todos os entes fracamente integrados à dinâmica metropolitana podem ser inseridos formalmente nas regióes, desde que os incentivos para sua participação não decomponham os estímulos correspondentes para a ativa contribuição dos entes que consomem a maior parcela de mal público.

\section{CONCLUSÃO}

Neste artigo, elaborei a percepção existente na literatura sobre regióes metropolitanas de que há problemas de ação coletiva persistindo como óbices à cooperação institucional entre os municípios componentes de tais áreas. Ao explicitar algumas hipóteses da tradição teórica da ação coletiva desde Olson, reforço a possibilidade de que essa teoria crie mais implicações observáveis para o teste empírico.

O modelo teórico resultante desse esforço é aplicado de maneira preliminar às regiões metropolitanas de Natal e Recife, mas claramente é possível usá-lo para as mais diversas situações metropolitanas. A única condição é que se possam formular questões relacionadas ao mal público metropolitano, conceito que criei para subsumir os diversos (e usualmente graves) problemas relacionados à convivência intermunicipal em metrópoles. A percepção desse mal é o pressuposto de toda cooperação globalmente relevante entre municípios nas RMs, e pudemos mostrar que, onde ele não incide, a participação dos entes municipais em conselhos gestores é somente mais uma esfera de oportunidade política para eles.

Outra contribuição que espero poder ter feito aqui reside no fortalecimento dos vínculos entre a literatura sobre governança metropolitana e sua congênere sobre arranjos socioespaciais e dinâmica econômica. O recado básico é que não dá pra separar uma coisa da outra na análise das RMs. Por isso mesmo, vinculei diretamente a variável de integração de municípios na dinâmica regional à emergência e solução de problemas cooperativos.

(Recebido para publicação em janeiro de 2010) (Aceito em fevereiro de 2011)

\section{REFERÊNCIAS}

ANDRADE, Ilza; CLEMENTINO, Maria. Descentralização e impasses da governança metropolitana. In: RIBEIRO, Luiz; SANTOS JÚNIOR, Orlando (Org.). As metrópoles e a questão social brasileira. Rio de Janeiro: Revan, Fase, 2007. p. 239-258.

ANDRADE, Ilza (Coord.). As relações intergovernamentais no contexto da governança metropolitana. Relatório de pesquisa. Natal: UFRN, 2008.

CLEMENTINO, Maria. Condições institucionais de cooperação entre os municípios metropolitanos. In: 
(Coord.) Como anda a Região Metropolitana de Natal. Relatório de Pesquisa. Natal: UFRN, 2005.

Municípios metropolitanos: os desafios do financiamento público. In: VALENCA, Márcio (Org.) Globalização e marginalidade. Natal: UFRN: IGU, 2008. Cap. 23.

; PESSOA, Zoraide. Tipologia socioespacial numa metrópole em formação: a RMNatal. In:

(Org.). Natal, uma metrópole em formação. São Paulo: Educ, 2009. p. 73-113.

; SOUZA, Maria (Org). Como andam Natal e Reci$\overline{f e . ~ R i o ~ d e ~ J a n e i r o: ~ L e t r a ~ C a p i t a l: ~ O b s e r v a t o ́ r i o ~ d a s ~ M e t r o ́-~}$ poles, 2009.

FEIOCK, Richard (Ed.). Metropolitan governance: conflict, competition and cooperation. Washington: Georgetown University Press, 2004.

GARSON, Sol. Regiões metropolitanas: por que não cooperam? Rio de Janeiro: Letra Capital, 2009.

GOMES, Rita. Dinâmica territorial no espaço metropolitano de Natal. In: CLEMENTINO, Maria; PESSOA, Zoraide (Org.) Natal, uma metrópole em formação. São Paulo: Educ, 2009. p. 49-71.

HARDIN, Garrett. The tragedy of the commons. Science, México, v. 162, p. 1243-1248, 1968.

HARDIN, Russell. Collective action. Baltimore: The Johns Hopkins University Press, 1982.
MOURA, Rosa et al. O metropolitano no urbano brasileiro: identificação e fronteiras. In: RIBEIRO, Luiz; SANTOS JUNIOR, Orlando (Org.). As metrópoles e a questão social brasileira. Rio de Janeiro: Revan, Fase, 2007. p. 127-155.

OLSON, Mancur. A lógica da ação coletiva: os benefícios públicos e uma teoria dos grupos sociais. São Paulo: Edusp, 1999.

ORENSTEIN, Luiz. A estratégia da ação coletiva. Rio de Janeiro: Revan: UCAM/IUPERJ, 1998.

OSTROM, Elinor. Governing the commons: the evolution of institutions for collective action. Nova Iorque: Cambridge University Press, 1990.

PESSOA, Zoraide. O movimento pendular na definição da espacialidade social e territorial da RMNatal. In: CLEMENTINO, Maria; PESSOA, Zoraide (Org.) Natal, uma metrópole em formação. São Paulo: Educ, 2009. p. 301-330

RIBEIRO, Luiz (Org.) Hierarquização e identificação dos espaços urbanos. Rio de Janeiro: Letra Capital: Observatório das Metrópoles, 2009.

SANTOS, Wanderley. Razões da desordem. 2.ed. Rio de Janeiro: Rocco, 1993.

SOUZA, Celina. Condições institucionais de cooperação na região metropolitana de Salvador. In: CARVALHO, Inaiá; PEREIRA, Gilberto (Coord.) Como anda Salvador e sua região metropolitana. Salvador: Edufba, 2006. p. 171-185. 


\section{COLLECTIVE ACTION AND INTERMUNICIPAL COOPERATION IN TWO METROPOLISES}

\author{
Alan Daniel Freire de Lacerda
}

This paper mainly aims to develop a theory of collective action relevant to the analysis of problems of metropolitan cooperation. Taking as such preliminary cases the metropolitan areas of Recife and Natal, this work also aims to establish which incentives municipalities belonging to such regions have to cooperate in solving typically intermunicipal problems. The theoretical and methodological choice of this paper leads to the conclusion that the issues related to metropolitan management can not be separated from variables related to the integration of the counties to the main city in the region. The empirical work done in the partial implementation of the model sistematizes qualitative and quantitative data from research done by others over the two regions mentioned.

KEYWORDS: cooperation, management, metropolises. MoTs-CLÉs: coopération, gestion, métropoles.

\section{ACTION COLLETIVE ET COOPÉRATION INTERMUNICIPALE DANS DEUX MÉTROPOLES}

\author{
Alan Daniel Freire de Lacerda
}

L'objectif principal de ce texte est d'élaborer la théorie d'une action collective capable d'analyser les problèmes métropolitains de coopération. Les régions métropolitaines de Natal et de Recife serviront de base pour une étude de cas préliminaire. La recherche se veut également de définir les supports dont disposent les municipalités qui forment ces régions pour apporter leur collaboration en vue de trouver une solution aux problèmes inter municipaux. Le choix théorique et méthodologique de cette étude mène à la conclusion que les questions liées à la gestion métropolitaine ne peuvent être séparées des variables relatives à l'intégration des communes avec la ville-pôle de la région. Le travail empirique, réalisé pour la mise en œuvre partielle du modèle, systématise les données qualitatives et quantitatives des recherches réalisées par d'autres auteurs sur les deux régions citées.

Alan Daniel Freire de Lacerda - Doutor em Ciência Política pelo IUPERJ e um estágio doutoral (sanduíche) na Duke University. Professor adjunto da Universidade Federal do Rio Grande do Norte, onde coordena o curso de graduação em Gestão de Políticas Públicas. Suas áreas de interesse acadêmico incluem relações executivo/legislativo, teoria política, partidos e eleições, governança intermunicipal. 